\title{
Neurocysticercosis and HIV Infection
}

\section{Neurocisticercose e infecção pelo HIV}

Beuy JOOB ${ }^{1}$, Viroj WIWANITKIT²

Dear Editor,

We read the publication on "Neurocysticercosis (NCC) and HIV Infection: what can we learn from the published literature?" with great interest ${ }^{1}$. Herrera Vazquez et al. concluded that "Our review did not reveal clear interactions between HIV and NCC. This may be partially due to the small number of cases and reliance on published research ${ }^{1}$." We would like to share ideas on this publication. First, Herrera Vazquez et al. mentioned that they reviewed the literature and could recruit only 40 cases of patients co-infected with NCC and HIV. In fact, the two conditions are not extremely uncommon in tropical countries and co-infection is sporadically seen. In a recent report from Tanzania, among 170 local villagers with seropositive HIV, NCC was found in three patients ${ }^{2}$. In fact, there is another interesting publication from Brazil showing that "Conditions related to the nervous system were the most commonly associated causes of death when NCC was mentioned as an underlying cause, and HIV/AIDS was the main underlying cause when NCC was an associated cause ${ }^{3}$." Regarding the clinical manifestation, asymptomatic NCC is not uncommon among HIV infected cases ${ }^{3}$. Some patients may have only subcutaneous parasitic cysts as the first presentation before further diagnosis of $\mathrm{NCC}^{4}$.

\section{References}

1. Herrera Vazquez O, Romo ML, Fleury A. Neurocysticercosis and HIV Infection: what can we learn from the published literature? Arq Neuropsiquiatr. 2019 May 1;77(5):357-65. https://doi.org/10.1590/0004-282×20190054

2. Schmidt V, Kositz C, Herbinger KH, Carabin H, Ngowi B, Naman E, et al. Association between Taenia solium infection and HIV/AIDS in northern Tanzania: a matched cross sectional-study. Infect Dis Poverty. 2016 Dec 1;5(1):111. https://doi.org/10.1186/s40249-016-0209-7
3. Martins-Melo FR, Ramos AN Jr, Cavalcanti MG, Alencar $\mathrm{CH}$, Heukelbach J. Reprint of "Neurocysticercosis-related mortality in Brazil, 2000-2011: Epidemiology of a neglected neurologic cause of death". Acta Trop. 2017 Jan;165:170-8. https://doi.org/10.1016/j.actatropica.2016.11.009

4. Agaba E, Modi D, Gunduz O, Modi Z. Subcutaneous nodules of cysticercosis as a sign of asymptomatic neurocysticercosis in an HIV positive patient. Rev Soc Bras Med Trop. 2018 Nov-Dec;51(6):861-3. https://doi.org/10.1590/0037-8682-0178-2018

'Sanitation 1 Medical Academic Center, Bangkok Thailand;

${ }^{2}$ Honorary professor, dr DY Patil University, Pune, India.

Correspondence: Beuy Joob; Sanitation 1 Medical Academic Center, Bangkok Thailand; E-mail: beuyjoob@hotmail.com BeuyJoob iD http://orcid.org/0000-0002-5281-0369; Viroj Wiwanitkit (iD http://orcid.org/0000-0003-1039-3728. Conflict of interest: There is no conflict of interest to declare.

Received 25 June 2019; Accepted 03 July 2019. 